\title{
Introducing Platform Interactions Model for Studying Multi-Sided Platforms
}

\author{
Kalina S. Staykova \\ Copenhagen Business School \\ kss.digi@cbs.dk
}

\author{
Jan Damsgaard \\ Copenhagen Business School \\ jd.digi@cbs.dk
}

\begin{abstract}
Multi-Sided Platforms (MSPs) function as sociotechnical entities that facilitate direct interactions between various affiliated to them constituencies through developing and managing IT architecture. In this paper, we aim to explain the nature of the platform interactions as key characteristic of any MSP. To this end, we propose the Platform Interaction Model (PIM), built upon Activity Theory and Business Action Theory. We then test its explanatory capability by applying it to four cases. Based on our analysis, we argue that MSPs enable various types of interactions, which has implications for the initial adoption, competitiveness, and subsequent expansion of particular MSP.
\end{abstract}

\section{Introduction}

Multi-Sided Platforms (MSPs), which function as complex socio-technical systems that facilitate direct interactions between various affiliated constituencies through developing and managing modular IT architecture (e.g., Apple's App Store, Airbnb, EBay, etc.), have emerged as some of the most predominant business models $[12,21]$. Despite their global spread and economic significance, the research on MSPs provides relatively little insights into the nature of this important phenomenon.

In particular, although the literature on MSPs emphasizes that the MSP's main source of value is its ability to facilitate the interactions between the affiliated to the platform participants [13, 15, 21], few researchers investigate the essence of platform interactions (see, below). Thus, our knowledge about the mechanisms, through which a platform creates, regulates and maintains the interactions between the affiliated to it platform constituencies remains scant. Apart from clarifying the mechanisms through which MSP creates value, understanding platform interactions as a key characteristic of MSPs is of vital importance when trying to explain the presence of various platform-based business models.

The importance of understanding platform heterogeneity is evident from the eBay-PayPal partnership, which was established when eBay bought PayPal in 2002, and later was dissolved in 2015 when the partnership seized to be perceived as mutually beneficial. Although both eBay and PayPal are defined as MSPs, eBay is an online marketplace for goods, whereas PayPal functions as payment platform. As payments were seen as "vital function in trading on eBay" [7], eBay sought to introduce an efficient payment method, which speeded up the settlement of eBay transactions [4], leading to the PayPal acquisition. Thus, while PayPal sees payments as the main value proposition it provides, eBay perceives payments as an additional element to its core value proposition or main interaction (that is, transfer of goods). This indicates that MSPs enable various types of interactions, which signals that their mechanisms for value creation and value capturing will also differ. Thus, we formulate the following research question (RQ): How does a MSP enable interactions between the affiliated to it distinct groups of participants?

To answer this RQ, we first construct the Platform Interaction Model (PIM) by integrating three distinct streams of literature and then test its explanatory power on four cases. The PIM allows us to explain the general nature of the interactions occurring on any MSPs, while it also allows us to take into account the existing platform heterogeneity. By comparing and contrasting the constructed models of platform interactions utilizing PIM, we can better understand the different types of existing platforms and the different manners in which they create, exchange and capture value. In this paper, we argue that establishing a difference in the nature of the platform interactions and the manner they are created and facilitated can constitute a key differentiator that can account for the observed platform heterogeneity.

This paper proceeds as follows: First, we outline the theoretical foundations of this paper. We, then, present the Platform Interaction Model, which serves as our analytical framework. As a next step, we 
briefly introduce the four investigated cases and analyze them. In the final sections of the paper, we discuss our findings, offer some conclusions and suggest promising areas for further research.

\section{Theoretical foundations}

\subsection{MSPs and platform interactions}

A MSP's value generation ability lies in its capability to enable multiple interactions that occur with high frequency among the affiliated to the platform participants [21]. Platform interactions are mainly investigated as being both content (object of interaction and actors who interact) and a process (execution of interaction). Hagiu and Wright [15] define platform interactions as "joint activities between distinct customer types” (p. 9). Thus, Hagiu and Wright [15] view the occurring platform interactions as a series of actions occurring between the affiliated to the platform participants communication (one-way or two-way), exchange, which includes sub-actions (distribution, price discovery and/or settlement (payment)), and consumption. Parker et al. [21], who see platform interactions as involving predominantly acts of matching and exchange, uphold this view.

Apart from being investigated as series of actions, platform interactions are also analyzed with regards to the value that is being created, communicated, exchanged and consumed on the platform [21]. Thus, Parker et al. [21] view platform interactions as a form of social or economic exchange of information, goods/services and currency, while Hagiu and Wright [15] emphasize on the platform interaction as consisting of exchange of goods, services and assets. The content view of platform interactions also states that platform interactions consist of the participants (producer and consumers of value), the value unit, and the filter, which ensures the relevance of the value delivered to particular consumers [21].

Despite these attempts to conceptualize the nature of platform interactions, there is a lack of analytical model, which bridges these two, often overlapping, views in one comprehensive model. In order to address this gap and to provide more thorough conceptualization of platform interactions, we adopt Activity Theory (AT) and Business Action Theory (BAT). We view platform interactions as occurring between various platform participants and as being mediated by the platform. Thus, we choose AT as it sheds light into the socio-technical nature of the platform interactions due to its theorization of the interactions taking place between economic actors and technology (that is, the platform). We also use BAT as this theory helps us conceptualize the interactions occurring between various economic actors.

\subsection{Activity theory}

AT, which initially emerged in Russian psychology [19, 25], is largely applied to the HCI field to study the interactions occurring between humans and IT systems. To the knowledge of the authors, there are no studies, which employ AT to understand the nature of MSPs interactions. AT defines interactions as an activity motivated by a goal (object) and performed by subjects, who employ tools, in order to achieve a certain outcome. For example, Rambe [22] views students creating posts on Facebook as subjects, contributing to knowledge building, which constitutes the object of their activity, by using technological tools provided by Facebook. Tools are defined as the mediating device by which the action is executed [16] and as "anything that mediates subjects' action upon an object" [23, p.70]. One of the main principles of AT is the hierarchical view of activity [18]. As Kaptelinin et al. [17] argue "activities, which are driven by motives, are performed through certain actions which are directed at goals and which, in turn, are implemented through certain operations" (p. 193). Although we adopt AT in order to understand the role of a platform as interaction mediator, the theory itself does not provide us with the necessary analytical tools to fully capture the nature of the interactions occurring between the affiliated to the platform economic actors (the interactions, which a platform mediates, are of economic nature, that is they occur between two economic actors). As Bækgaard [3] points out AT is usually not applied to study the interactions between economic agents mediated through technology.

\subsection{Business action theory}

In order to investigate the interactions taking place between the various economic actors participating on the platform, we build upon the BAT, which advocates that the interactions between economic actors occur at different stages establishing business prerequisites, exposure and contact search phase, proposal phase, contractual phase, fulfilment phase and assessment phase $[1,10]$. The BAT Stage Model emphasizes that all actors involved (suppliers and customers) perform generic acts in order to carry out a business transaction (offer, order, delivery, payment, assessment) $[1,10]$. Thus, a 
business interaction is mutually constructed and executed. Although the BAT model recognizes the dyad and iterative nature of the occurring business interactions [1], it does not take into account the presence of network effects, which define platform interactions. The BAT model is also mainly applicable to consumer-to-business (C2B) and business-to-business (B2B) interactions, thus excluding consumer-to-consumer (C2C) interactions, which constitute significant part of the interactions occurring on certain platforms (e.g., Facebook, YouTube, Airbnb, etc.). To address these limitations, we adapt some of the main principles of the BAT model to the main MSPs principles.

\section{Platform interaction model}

In order to answer the above posed research question, we investigate the nature of the interactions which occur between the affiliated to the platform distinct groups of participants. To this end, we propose the Platform Interaction Model (PIM), actors (that is, platform participant affiliated to the platform and platform owner itself) in engaging and performing these operations (see, section 2.3), which become central for executing platform interactions. Thus, we acknowledge that all of the affiliated to the platform groups of participants (fig. 1, A and B) and the platform itself (fig. 1, C) are engaged in executing certain sets of operations (e.g., uploading a video on YouTube, writing a comment on Facebook, displaying search results (platform)) in order to achieve certain goal-oriented actions. For example, eBay facilitates the exchange of goods between a seller and a buyer, which constitutes the core interaction on the platform. The actual sale of goods commences when buyers (fig. 1, A) search for given category of goods (operation A) and browse the relevant offers displayed by the platform (operation C) based on the available items previously uploaded by sellers (operation B). The purpose of executing these operations is the selection of the most relevant offer (matching). Thus, the successful completion of set of operations leads to the achievement of goaloriented actions, which are defined and designed by

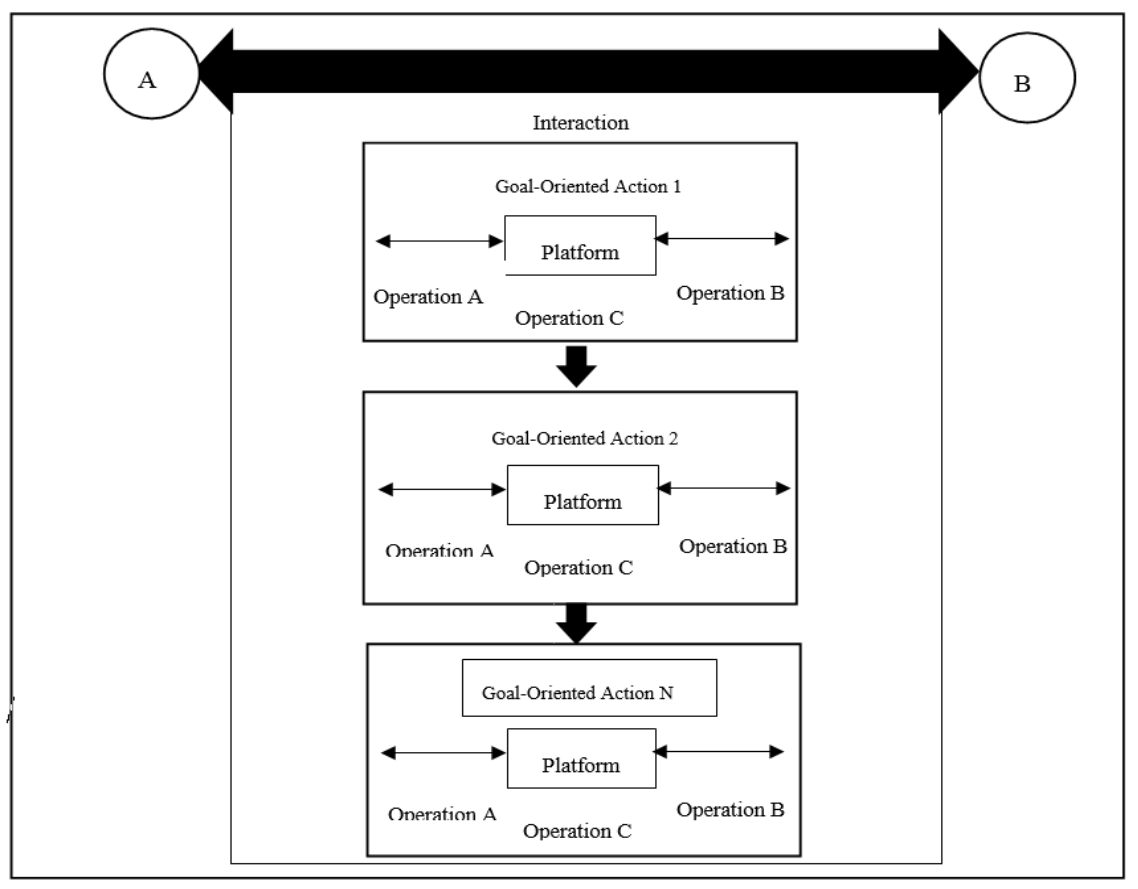

Figure1. Platform interaction model

which investigates the platform interactions as both content and process and which serves as an analytical tool guiding our research.

Building upon AT, we view platform interactions as hierarchical activity consisting of several goaloriented actions, each of which consists of a number of separate operations (see, fig. 1). Utilizing BAT, we emphasize on the role of the platform economic the platform (e.g., value unit production, matching, consumption, etc., (see [21]), and which are needed for the completion of the core interaction enabled by the platform.

\section{Method}


In order to provide an answer to our research question, we use a qualitative research method utilizing comparative case study analysis. Case studies aim at providing in-depth understanding of complex phenomena by allowing researchers to analyze them amidst their context of emergence and existence [2], based on collection and detailed analysis of various data sources [27].

In order to conduct our comparative case study research, we select four MSPs - two MSPs, which function as marketplaces, and two payment platforms. We choose to investigate two different types of platforms (marketplaces and payment platforms) in order to demonstrate the applicability of the PIM model in capturing diverse platform interactions. We further decide to analyze two cases of each platform type in order to ensure that our findings are consistent. The basis for case selection is the types of interactions, which emerge between certain types of actors. Thus, we choose to study a platform, which supports $\mathrm{C} 2 \mathrm{C}$ interactions (Uber), and a platform, which enables $\mathrm{C} 2 \mathrm{~B}$ interactions (Groupon). We then select two payment platforms Pingit, which initially supported only $\mathrm{C} 2 \mathrm{C}$ payment transfers before enabling C2B payments, and Apple Pay, which supports $\mathrm{C} 2 \mathrm{~B}$ payment transactions.

We rely on secondary data, which provide insights into the functioning of the investigated platforms. In order to capture the interactions occurring on and through the platform, we collect their respective terms and conditions, where the exact functioning of a platform is documented, as well as descriptions of platforms' services from their commercial websites and app stores and any additional information published under support or Q\&A sections.

To conduct the data analysis, we identify the affiliated to the platform groups of participants (who), the possible interactions they can engage with through the platform (what) and how such interactions are carried out (how). When analyzing the execution of the specific interactions (how), we have tried to identify the set of operations performed by various platform participants, which form goaloriented actions. We then use the information obtained from the collected data in order to create a model outlining the interactions, which occur on a MSP (see fig. 2 and fig. 3). We focus mainly on identifying the core interaction(s), or the interactions, which represent the main purpose (functionality) of the platform (Parker et al., 2016). Thus, we exclude additional interactions, such as "ask for refund on eBay", which, although part of the functionalities of a platform, do not occur on constant basis.

\section{Interactions on marketplaces as types of MSPs}

We use Uber and Groupon as exemplary cases to illustrate the interactions occurring on marketplaces as specific platform types. We apply the PIM model in order to explain the interactions taking place on these two similar platforms, which function as marketplaces. We conduct the analysis of the two cases simultaneously in order to validate the application of the PIM model to this particular platform type (see, section 5.3).

\subsection{Uber}

The popular ride-sharing app Uber was launched in 2009 with the purpose to revolutionize the manner in which people commute. Utilizing the principles of sharing economy, Uber offers predominantly nontaxi driving rideshare services, which allow a rider to easily identify available driver in nearby vicinity, communicate with them (book a ride, show pick-up location, etc.) and pay for the ride. More than one million rides are booked through Uber on a daily basis around 540 cities worldwide [24].

\subsection{Groupon}

Groupon, launched in 2008, functions as online marketplace where consumers can buy coupons and discount offers provided by various local merchants. Groupon's main goal is to help consumers discover and connect to various businesses, which provide relevant for them services at discounted prices. Thus, Groupon delivers value to both users by allowing them to explore their local community and to merchants, who wish to acquire new customers and drive their sales. In 2016, Groupon counted 50 million customers across 26 countries.

\subsection{Cases analysis}

Uber functions as one-sided platforms as it facilitates the interactions between economic actors with interchangeable roles - people who seek a ride (riders) and non-professional drivers. Groupon functions as two-sided platform mediating the interactions between two distinct groups of participants who cannot interchange their roles consumers and merchants.

Despite affiliating different types of economic actors, the two platforms ultimately connect producers and consumers of value (see fig.2, Actor A and Actor B). Based on the BAT and AT principles, 
we present the platform interactions occurring on Uber and Groupon as an activity consisting of different phases - affiliation, value creation, match discovery, match making, match realization, match settlement, match evaluation (see fig. 2), which platform's main goal (providing a ride (Uber) or finding relevant deal from merchants (Groupon). The same analysis is applied to the other activities performed in order to execute an interaction - match making, match realization, match settlement, match

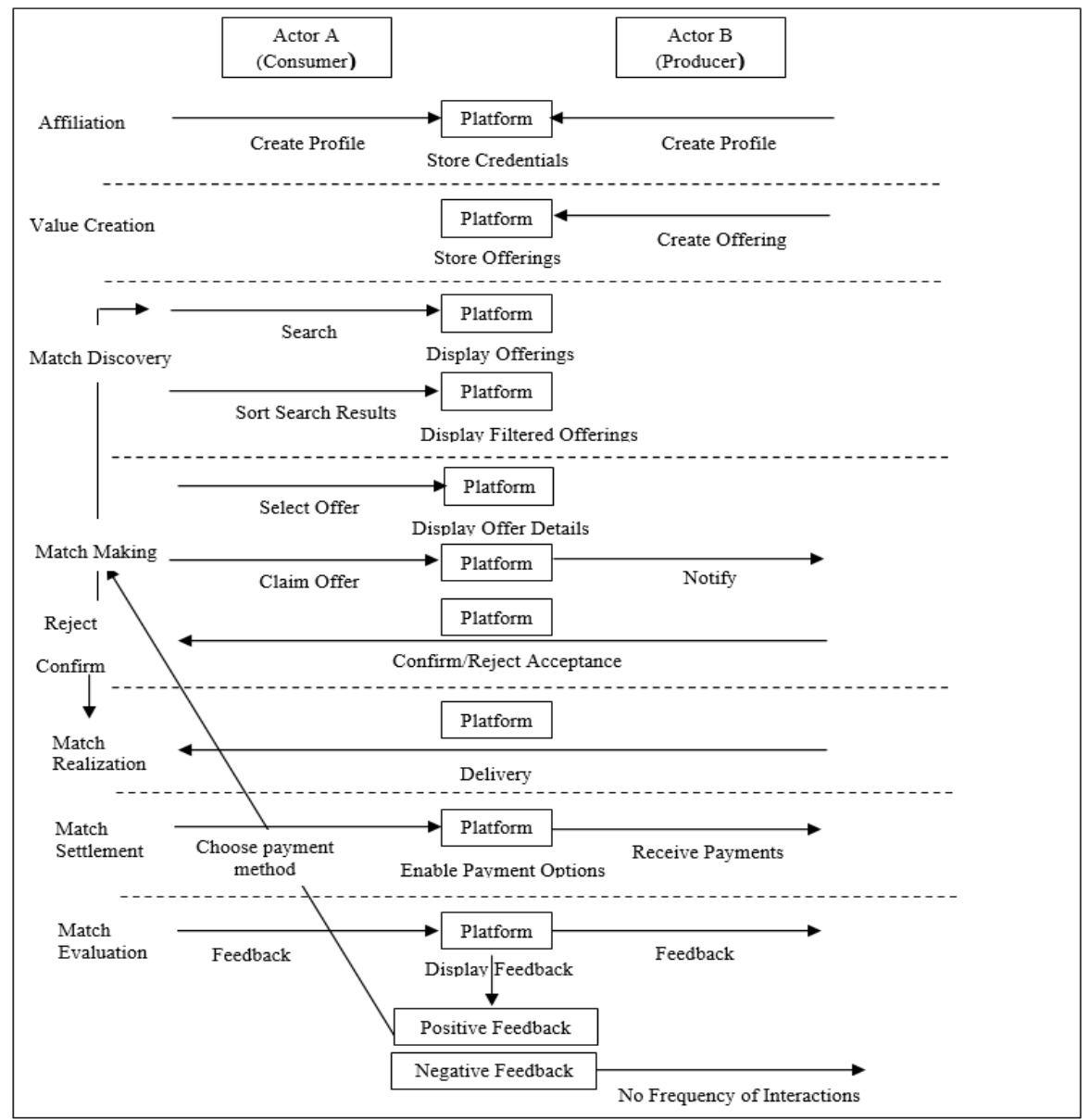

Figure 2. PIM for Uber and Groupon

platform actors go through in order to create, exchange and consume value. Each of these phases represent different actions executed for the achievement of sub-goals, which together are directed towards the realization of the platform's main goal - executing core interactions with certain frequency. These actions consist of separate operations, which are performed by the affiliated to the platform participants (either producers and consumers, or both) and mediated through the platform. For example, both Uber and Groupon enable users (usually the consumer, Actor A) to perform certain amount of operations (search, sort searches), which are facilitated by the platform (display (filtered) offerings) and directed towards performing specific actions in order to achieve a subgoal (match-discovery) with the aim to realize the evaluation. The first two phases - affiliation and value creation, are considered as prerequisites for the execution of a frequent interaction (connecting riders and drivers, or consumers and merchants).

Affiliation is one-time action, which consists of one-time operation (creating a profile), whose main goal is to receive access to the services provided by the platform (see fig. 2). Value creation is also seen as one-time action, where the producer creates its value unit [21] (provides description of their car or offer in order to make it available on the platform) as a pre-requisite for the next action - the match-making - to commence (see fig.2).

The model, presented on fig. 2, captures the iterative nature of the MSPs interactions. The matchmaking action, whose goal is the creation of a match, consists of two options (operations), which determine 
whether this particular goal-oriented action is complete or not. In case of completion (see fig. 2, accept), actors proceed to the next phase of the model- match realization. In case of non-completion, the consumer begins a search of new producer and repeats the match-making phase. The last action match evaluation, serves as a basis for the creation of future interactions between the producer (actor B) and existing or new consumers (actor A). Thus, the match evaluation increases the chances of subsequent match-making, and thus reinstates the iterative nature of the MSPs interactions.

\section{Interactions on payment platforms}

\subsection{Pingit}

In 2012, the UK-based Barclays bank launched its peer-to-peer transactions (P2P) app Pingit which allows one user to send money to another user fast, easily and efficient. The service is available for Barclays' customers and non-customers provided they have a UK current bank account and a UK mobile phone number. Approximately 4.2 million people have signed-up for the service since its launch. Pingit has also managed to attract 67000 businesses so far [20]. Initially launched as being one-sided, Pingit later expanded to become two-sided platform in May 2012.

\subsection{Apple Pay}

Apple Pay is a digital wallet service launched in October 2014 by Apple. Customers, who have the latest version of Apple's iPhone (iPhone 6 and iPhone 7), can use Apple Pay in order to execute instore payment transactions at the premises of merchants, who are equipped with contactless payment terminals. The solution was initially launched in the USA and later made available in 11 other markets, such as UK, Canada, Japan, etc. Soon after its initial release, Apple Pay managed to attract app. 1 million users who registered their payment cards in the solution [26].

\subsection{Cases analysis}

The main value proposition of the two investigated payment platforms - Pingit and Apple Pay - is to facilitate the transfer of money among the various affiliated to the platform participants. Although the groups of participants affiliated to the two payment platforms seem identical, namely senders (buyers) and receivers (sellers) of money, a detailed analysis of the types of interactions, which these payment platforms enable, indicates for the presence of a certain difference. Pingit was initially launched as one-sided platform, enabling the interactions between one distinct group of participants with interchangeable roles (senders and receivers) (see fig. 3, P2P payment transfer). Initially, Pingit supported two types of interactions - allowing users to send money to receivers and allowing users to request money from other users. In order to execute a P2P payment transfer (fig. 3, send payments), which constitutes the main activity initially supported by Pingit, a sender performs a series of operations - chooses a recipient based on the receiver's phone number (fig. 3 (a), enters the required amount to be sent, adds a personal message or attaches a photo after which the user confirms the payment. In case a sender is not aware of the number of the recipient, the user can request it via channels outside of the payment platform (fig. 3 (b)). This is the only possible interaction occurring outside of the payment platform, with the majority of the interactions mediated through the payment platform. The payment request is sent to the platform provider, which initiates a process of transferring funds from the bank account of the sender to the bank account of the designated receiver. Upon completion of this process, the receiver of funds is notified with a message sent out by Pingit after the payment platform has verified whether such a transaction can occur or not (e.g., availability of funds, anti-fraud, etc.). As part of the $\mathrm{P} 2 \mathrm{P}$ interaction, a user can request a payment by entering a contact information, amount and justification for payment before forwarding this message to Pingit, which distributes it to the potential debtor. The recipient of the message can proceed with transferring the requested funds by following the series of actions required for sending payments.

P2P interactions, however, are not present on Apple Pay as, for the time being, Apple Pay's users cannot execute P2P transfers. Instead, Apple Pay chooses to focus on facilitating the interactions between two distinct groups of participants, namely consumers and merchants (see fig. 3, C2B payment transfer). C2B interactions are also enabled on Pingit after the payment platform added merchants as a second distinct group of participants, thus transforming into being a two-sided platform. As stated above, payment platforms can be launched as one-sided platforms and later transformed into being two-sided in the course of their evolution, or be launched as two-sided platforms from the onset. The analysis of both Pingit and Apple Pay demonstrate 
that the transfer of money between consumers and merchants can be facilitated by different payment payment information is captured by the payment platform as mediator of the $\mathrm{C} 2 \mathrm{~B}$ interaction (e.g.,

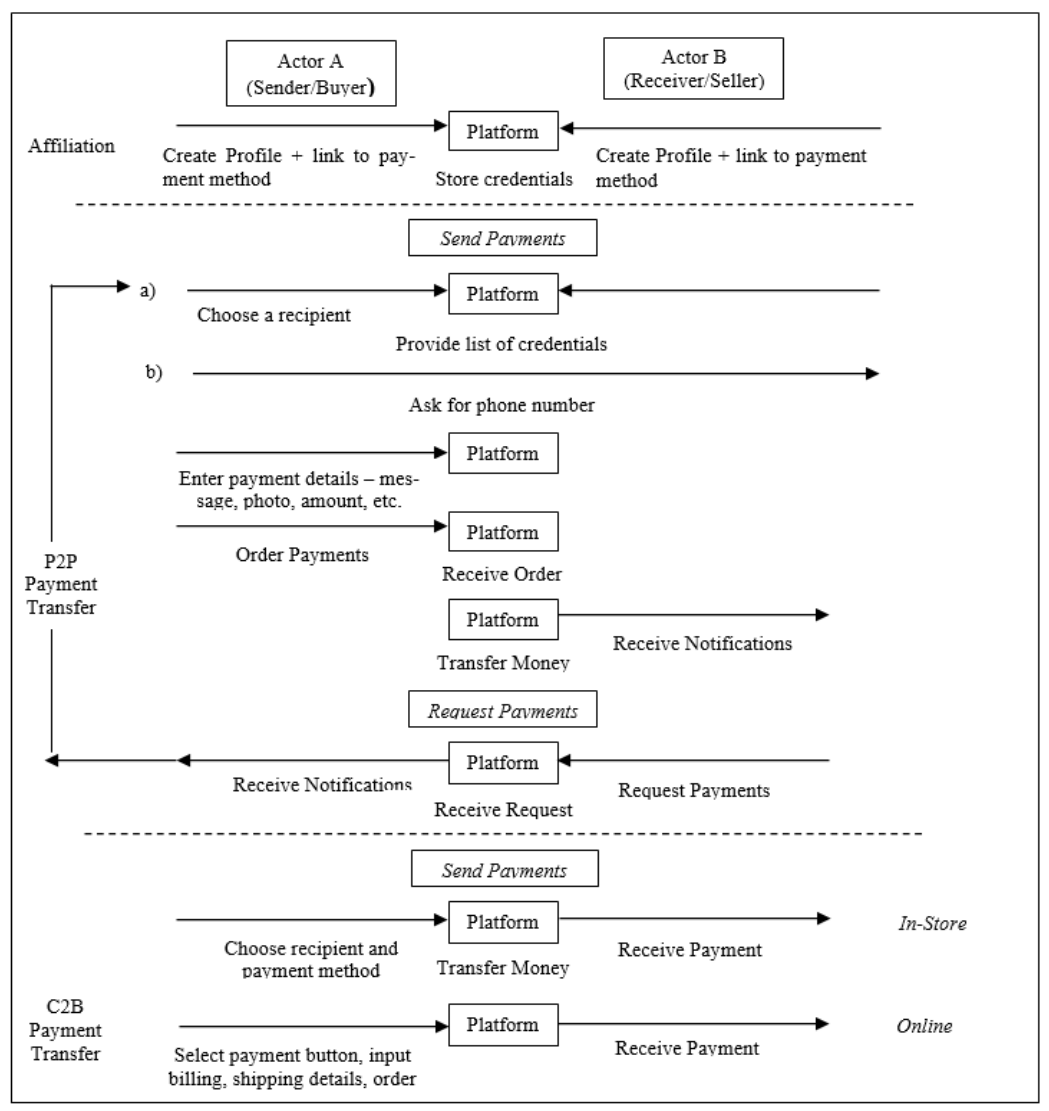

Figure 3. PIM for digital payment platforms

methods depending on various payments scenarios. As the different merchants possess different characteristics and have different payment needs (online, offline, small and large), a payment provider needs to develop and support an array of payment options in order to facilitate the interactions between consumers and merchants (fig. 3, C2B payments, instore and online payments). Thus, payment platforms support either $\mathrm{P} 2 \mathrm{P}$ and $\mathrm{C} 2 \mathrm{~B}$ transactions or just one of them (e.g., C2B for Apple Pay).

The payment transfer constitutes a goal-oriented action, which consists of separate operations performed by receiver or/and senders and mediated through the payment platform. The main difference between $\mathrm{P} 2 \mathrm{P}$ and $\mathrm{C} 2 \mathrm{~B}$ is the manner of adding recipients, that is how the payment details of specific merchant are accessed by the payment platform, so that a transfer can be initiated. For example, Pingit supports five different methods from which a user can choose in order to access the merchants' payment information - phone number, business directory, Twitter handle, short codes, and QR codes. The user scanning a QR code through the Pingit app or phone number stored in the business directory) after which this information is combined with transaction authorization and transmitted towards the receiver of funds.

Thus, there is no real exchange of payment information between consumers and merchants as the payment information of merchants is stored on the payment app during the initial process of platform affiliation. In order to initiate a transfer of money, the sender does not need to know the exact payment details, but rather a proxy under the form of phone number, QR code, and name in the business directory. The platform provider itself usually prompts this proxy to the user. Thus, the initial payment details are exchanged with the payment platform, which simplifies them by adding them to a proxy and later when needed displays them in easily accessible form for the user to find. For example, Pingit allows users to add merchants as payment recipients by looking them up in a business directory by their name. 
The $\mathrm{C} 2 \mathrm{~B}$ interactions in online environment (see fig. 3, C2B payment transfer, online payments) are not initiated from the payment platform, but rather from a third-party app or website where a payment button (e.g., Pay with Apple Pay or Buyit with Pingit) redirects the user to the specific payment platform. Thus, in online $\mathrm{C} 2 \mathrm{~B}$ payment transfer, the selection of recipients as well as obtaining the payment details of a merchant are already known to the payment platform for the execution of specific payment transaction. The only information required from a user to input is billing and shipping address if applicable.

An analysis of fig.3, which presents the main interactions occurring on payment platform as a series of separate, interrelated actions, demonstrates that payment platforms are engaged predominantly in mediating the exchange of money using proxies, which replace cumbersome payment details (e.g., card numbers). Thus, we argue that the payment platforms do not possess distinct matching capabilities when performing either $\mathrm{P} 2 \mathrm{P}$ or $\mathrm{C} 2 \mathrm{~B}$ payment transfers.

\section{Discussion}

The analyzed case studies investigate the interactions occurring on two types of platforms marketplaces and payment platforms. In order to conduct our analysis, we study platform interactions represented as activities consisting of goal-oriented actions performed through a series of operations executed by either one or both of the affiliated actors and facilitated by the platform provider.

\subsection{The nature of the difference}

A comparison of the two models (fig.2 and fig.3) clearly demonstrates a difference between payment platforms and marketplaces concerning the nature of interactions they enable. The main interactions on marketplaces consist of multiple phases - match discovery, match making, match realization, match settlement, match evaluation (fig. 3), while payment platforms enable mainly payment transfers (or focusing on match realization) (fig. 2 shows that payments are used for settlement of transactions of some value (goods or services)). Thus, the nature and scope of interactions differs between the two types of platforms.

The key difference is the lack of match-discovery, match-making and match-evaluation capabilities supported by a payment platform (see fig. 3). We did identify certain elements, which could equip a payment platform with match-making capabilities, such as the presence of a business directory in Pingit and list of merchants accepting Apple Pay, found on the Apple Pay's website. However, we argue that they do not enable a platform with match-making capabilities, but are rather used for facilitating the execution of payment transfer by making it easier for users to add payment details.

Payment platforms do not possess a feedback mechanism to evaluate possible experience, which we see mainly as an aftermath of the lack of matching capabilities. The mechanisms for delivering value also differ as the value delivery on MSPs often takes place outside the platform (physical ride, delivery of goods by mail, etc.), while payments are always executed through the payment infrastructure supported by the payment platform. A comparison between the prerequisite phases needed for the execution of core platform interaction (compare fig. 1 and fig. 2, affiliation, value creation) demonstrates that while a MSP requires two separate actions of affiliation and value creation, payment platforms merge the two actions. This is due to the fact that when users undertake a process of platform affiliation, they are also required to provide their payment details (value creation (see, Parker et al., 2016).

\subsection{Why does the difference occur?}

An interesting question for discussion is why this difference occurs. In order to provide an answer, we compare digital and physical MSPs. A shopping mall and a town marketplace function as physical MSPs, allowing buyers and sellers to meet and interact in a physical environment. These platforms reduce search costs for the two parties and enable one group of participants to get access to other groups of participants [12]. Town marketplaces and shopping malls bring people together in one designated space, but finding the right merchant to buy goods from in terms of best price, quality, and previous reputation is not an easy task as these physical marketplaces do not provide such tools. Thus, match-discovery and match-making capabilities in physical environment are either not supported, or supported in limited manner. In contrast, in online marketplaces, finding the right merchant in the right category and comparing them in terms of prices and checking their reputation based on customer feedback enables the match-making capabilities of a platform, an action which was not previously possible in an offline environment. Thus, the digitalization of physical platforms equips them with match-discovery and match-making capability, and thus makes the 
interactions between the affiliated groups of participants more efficient.

The digitalization of payments, however, is focused on making the transfer of money from one party to another more efficient (or making "match realization" more efficient, see fig. 2). Thus, new technologies are employed in making a payment transaction faster, more convenient and more secure (the delivery of payments), but it does not lead to better discovery of relevant merchants or better matches between receivers and senders of money. Thus, unlike other platforms, which have made the transition towards digitalization by employing new technologies to deepen the interaction by adding new elements (match-discovery and match-making, instead of just supporting exchange of goods and services), payment platforms utilize technologies to improve the thing that they were already doing exchange of money.

\subsection{Does the difference matter?}

We argue that the difference observed in the nature of interactions enabled on payment platforms and on marketplaces is of certain significance. We further argue that such a difference has implications concerning the initial payment platform adoption and the subsequent innovation and expansion strategy of a payment platform. Evans and Schmalensee [8] point out that the majority of the payment platforms enabling C2B transaction, such as Apple Pay, has failed to ignite as they do not address significantly important friction. They argue that credit cards, such as Visa and MasterCard, are already providing efficient and secure payment methods; thus, bringing payments to the mobile phone does not provide additional value to consumers in any way. This is due to the fact that, as we claim above, the two investigated payment platforms (Pingit and Apple Pay) focus on enabling mainly payment transfers without trying to provide additional value to both users and merchants, such as allowing users to discover relevant merchants, and thus, for example, bringing new customers to merchants. It is true that certain payment platforms (e.g., Pingit) have managed to obtain significant user base (mainly from $\mathrm{P} 2 \mathrm{P}$ transactions, rather than $\mathrm{C} 2 \mathrm{~B}$ transactions), but this success can be jeopardized in the future if a payment platform cannot continue to evolve. This leads to the next question - should a payment platform be pre-occupied with concerns about merchant discovery and matching since its main value proposition lays in offering payments? Apart from being able to address an unserved (or poorly addressed) friction, a payment platform which focuses on match-making also increases its chances of being selected as preferred payment method. This is due to the specific nature of payments - payments constitute a settlement of value exchange (e.g., exchange of goods or services). Thus, payments are not the beginning of an interaction between a buyer and a seller but rather its end. Due to the nature of the services they provide, payment platforms, however, become part of such an interaction only when a seller and a buyer have to settle their transaction. Thus, for the most part, $\mathrm{C} 2 \mathrm{~B}$ transactions between economic actors take place outside a payment platform. Most retailers, however, support multiple payment options, and users often multi-home between payment instruments (having Visa and MasterCard, while also having Apple Pay and PayPal and even cash). When a user and a merchant have to settle a transaction, they can choose from a myriad of payment instruments to do so, thus leaving these payment solutions to compete. In order to overcome such a competition, a mobile payment solution should enhance its value proposition with match-discovery and match-making capabilities in order to internalize the interaction occurring between merchants and consumers. The higher the chance that a match between users and merchants will be realized on a payment platform, the higher the chance that this transaction will be settled on that particular payment platform.

\section{Conclusion}

In this paper, we aim to explain the nature of MSPs interactions. We contribute to the literature on MSPs as we offer an attempt to conceptualize platform interactions as main source of value creation on MSPs by building upon AT and BAT. To this end, we build a Platform Interaction Model, which can be applied to study various types of interactions occurring on MSPs by integrating the two existing views on platform interactions (namely, as a content and as a process). We also propose an approach to study platform heterogeneity by focusing on platform interactions as a differentiator, which could provide an explanation of the observed variety of existing MSPs. We also contribute to the literature on digital payments as a type of MSP by providing insights into their nature and the limitations, which stem from it.

Our research is not without limitations. We focus solely on platform interactions as the main differentiator between payment platforms and MSPs, and thus, exclude other factors, which may also contribute to such difference (e.g., regulation). We also choose to study the main (or core) interactions facilitated by the platform. As MSPs evolve over 
time, they enable new types of interactions by bringing new distinct groups of actors to the platform (e.g. Pingit offering giftcards), which could constitute the addition of match-making capabilities. As such subsequent (or secondary) interactions do not constitute the core platform interaction, we do not focus on them in this study. Future work may address this shortcoming.

\section{References}

[1] Axelsson K., Goldkuhl G., and Melin U. "Using Business Action Theory for Dyadic Analysis", 10th Nordic Workshop on Interorganisational Research, Trondheim, Norway, 2000.

[2] Baxter, P. and Jack, S. "Qualitative Case Study Methodology: Study Design and Imple-mentation for Novice Researchers," The Qualitative Report, 13 (4), 2008, pp. 544-559.

[3] Bækgård, L. "Interaction in Information Systems beyond human computer interaction". In: Proceedings of ALOIS 2006, 257-272. University college of Borås: Borås, Sweden. http://www.vits.org/?pageId=317, 2006.

[4] CNET. "Billpoint failure a lesson for eBay?" URL: https://www.cnet.com/news/billpoint-failure-a-lesson-forebay/ (visited on: 09/10/2016), 2012.

[5] Dahlberg, T., Guo, J., and Ondrus, J. “A critical review of mobile payment research." Electronic Commerce Research and Applications, 14 (5), 2015, pp. 265-284.

[6] Dahlberg, T., Mallat, N., Ondrus, J., and Zmijewska, A. "Past, present and future of mo-bile payments research: A literature review." Electronic Commerce Research \& Applications, 7(2), 2008, pp. 165-181.

[7] eBay. "eBay to Acquire PayPal". URL: https://investors.ebayinc.com/releasedetail.cfm?releaseid=8 4142 (visited on 10/10/2016), 2002.

[8] Evans, D. S., and Schmalensee, R. Matchmakers: The New Economics of Multisided Platforms. Watertown, MA: Harvard Business Review Press, 2016.

[9] Gannamaneni, A., Ondrus, J., and Lyytinen, K. "A Post-Failure Analysis of Mobile Payment Platforms". In System Sciences (HICSS), 2015 48th Hawaii International Conference on (pp. 1159-1168). IEEE.

[10] Goldkuhl G. "The Six Phases of Business Processes Business Communication and the Exchange of Value". 12th Biennial ITS (ITS'98) conference - Beyond convergence, Stockholm, Sweden, 1998.

[11] Groupon. "Groupon Q2 2016 Public Fact Sheet", 2011.
[12] Hagiu, A. "Strategic Decisions for Multi-sided Platforms," MIT Sloan Management Review 55 (2), 2014.

[13] Hagiu, A. "Multi-Sided Platforms: From Microfoundations to Design and Expansion Strategies," Working Paper 07-094, Harvard Business School, 2006.

[14] Hagiu, A. and Rothman, S. "Network Effects Aren't Enough.” Harvard Business Re-view, April 2016, pp. 6471.

[15] Hagiu, A., and Wright, J. "Multi-Sided Platforms." Harvard Business School Working Paper 12- 024, 2011.

[16] Hasan, H. "Activity Theory: a Basis for the Contextual study of Information Systems in Organisations." In Information Systems and Activity Theory: Tools in Context (pp. 19-38). Wollongong: University of Wollongong Press, 1998.

[17] Kaptelinin V., Kuutti K., and Bannon L. "Activity theory: Basic concepts and applications." HumanComputer Interaction. Lecture Notes in Computer Science, 1995, pp. 189-201.

[18] Kaptelinin, V, and Nardi, B.A. "Activity theory: basic concepts and applications." CHI'97 Extended Abstracts on Human Factors in Computing Systems, 1997, pp. 158-159.

[19] Leontiev, A.N. Activity, Consciousness, and Personality. Prentice-Hall, Englewood Cliffs, 1978.

[20] Moore, M. "Zapp Takes The Fight To Apple Pay With Barclays Pingit Deal”, 2015.

[21] Parker, G., van Alstyne, M. and S. P. Choudary. Platform Revolution: How Networked Markets Are Transforming the Economy and How to Make Them Work for You. NY: WW Norton Company, Inc., 2016.

[22] Rambe, P. "Activity theory and technology mediated interaction: Cognitive scaffolding using question-based consultation on Facebook." Australasian Journal of Educational Technology, 28(8), 2012, pp. 1333-1361.

[23] Russell, D. R. "Looking beyond the interface Activity Theory and distributed learning." In M. Lea, \& K. Nicoll (Eds.), Distributed learning social and cultural approaches to practice (pp. 64-82). New York: RoutledgeFalmer, 2002.

[24] Uber. "Our Commitment to Safety", 2002. URL: https://newsroom.uber.com/our-commitment-to-safety/

[25] Vygotsky, L.S. Mind and Society. Harvard University Press, Cambridge, 1978.

[26] Worland, J. “Apple Pay Registers 1 Million Credit Cards in 3 Days", 2015

[27] Yin,R., K. Case study research: Design and methods, 3rd Edition. Thousand Oaks, CA: Sage, 2003. 